EUTOMIA

Revista de Literatura e Linguística

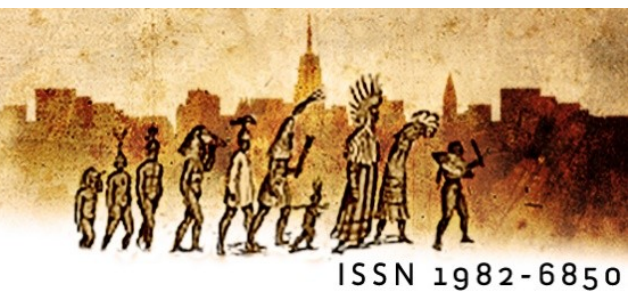

\title{
Intuição teórica / antropologia filosófica: $O$ arco intuitivo de Luiz Costa Lima em busca da mímesis
}

\section{Theoretical intuition / philosophical anthropology: Luiz Costa Lima's intuitive arch in search of mimesis}

\author{
Maycon da Silva Tannis ${ }^{\mathrm{i}}$ - (PUC-RJ)
}

\begin{abstract}
Resumo: Desde que começou a empreender o esforço para a compreensão do fenômeno do literário, Luiz Costa Lima realiza um longo arco figural em relação às suas perspectivas. Neste percurso, um importante corte atravessa seu pensamento: aquele que nos leva a enxergar, no caminho percorrido pelo autor a partir de uma perspectiva kantianamente definida da intuição como suplementação do pensamento, uma possibilidade de vermos o seu trabalho como uma proposta que se abre para uma Antropologia Filosófica.
\end{abstract}

Palavras-Chave: intuição, antropologia filosófica, arco figural.

\begin{abstract}
Ever since he began to undertake the effort to understand the phenomenon of the literary, Luiz Costa Lima makes a long figural bow in relation to his perspectives. In this trajectory, an important cut crosses his thinking: the one that makes us see the path taken by the author from a defined Kantian perspective of intuition as a supplementation of thought, a possibility enabling one to see his work as a proposal leading to a philosophical anthropology.

Keywords: Intuition, philosophical anthropology, figural bow.
\end{abstract}

Mattina

M'illumino d'Immenso.

Giuseppe Ungaretti

Se fôssemos hoje fazer uma longa consideração sobre a mimesis em Luiz costa Lima veríamos um objeto quase pronto e executável. Uma vez que o leitor, ao se aproximar da obra consegue compreender um arco orientado que avança, ao longo de quase quarenta anos, sobre a mimesis e sua compreensão no Ocidente. Percebe que a produção não segue 
uma ordem linear organizada e de como, mais recentemente, a teorização penetra mais profundamente.

A consideração redonda que nós faremos nos dará condições de entender o objeto que se constrói - a mimesis - e a peculiaridade com que isso é feito. Essa percepção é colhida de entrevista recente do autor na Revista de Teoria da História. O que se apresenta na entrevista é uma fala de Luiz Costa Lima sobre a duplicidade do conceito de controle, negativo e positivo, e de como a caracterização que veio fazendo do fenômeno mimético o leva a senti-lo acolhido pela Antropologia Filosófica. Mas essa sensação só se aguça pela caracterização de "criatura carente" (mängelwesen) e pelo papel desempenhado pela "metaforologia" de Hans Blumenberg. Ora, segundo o autor, o tanto a abordagem de Herder quanto a indagação metaforológica do filósofo alemão lhe haviam sido desconhecidas quando trabalhava o controle do imaginário. Ou seja, a teorização da mimesis incorporou, em um momento relativamente avançado de seu questionamento, duas ferramentas que serão decisivas para seu proposto reconhecimento.

É curioso que o conceito de "criatura carente" provenha de Herder, o mesmo autor que, no Metacrítica, manifestava a mais profunda recusa do pensamento de Kant, o suporte mais extenso do que tenho procurado desenvolver. [...] Assim, ao escrever $\mathrm{O}$ controle do imaginário, não tinha ideia nem da "criatura carente", nem do sujeito autocentrado, ou que aquela fora tematizada antes deste. (GUEDES et Al. 2018. p. 251-252.)

O que pode parecer uma simples negativa corretiva por parte do autor em relação à sua obra, se refere a uma atitude maior, primeiramente em relação ao caráter da escrita e pensamento teóricos em sua obra, pois a partir disso a Trilogia do Controle, um estudo sobre a especificidade do controle do imaginário e como a sociedade ocidental se monta em torno disso. Por outro lado, temos um elemento que nos é bastante interessante, uma vez que reconhecendo o esforço teórico de Luiz Costa Lima em suas últimas obras para compor outras faces da teorização da mimesis em relação à sua proximidade da antropologia filosófica não se verifica diferenças substanciais em relação aos momentos de escrita onde o autor não conhecia essa corrente de pensamento. Como é feita a passagem, nos dá uma impressão de que a obra se confunde com aspectos da biografia intelectual de Luiz Costa Lima, tomada é claro, dentro da compreensão de R. G. Collingwood, onde o autor escreve que a "biografia de um intelectual é a sua produção" (COLLINGWOOD, 2002, p.38); que no caso de sua obra pode ser vista como uma unidade não evolutiva, mas costurada por um 
arranjo intuitivo a moda da consideração Kantiana. O que demonstra não só esse [des]contínuo em relação a sua produção, mas que a teorização da mimese e do controle, são partes de um conjunto maior que corresponde a uma proposta mais ampla: a de uma antropologia filosófica [costalimenha].

Em uma formulação mais recente sobre a compreensão do que é o controle do imaginário sobre o qual Luiz Costa Lima escreveu primeiramente em sua obra O Controle do Imaginário onde o mesmo já escreve sobre a proscrição da mimesis como elemento criador e não de mera cópia. Dentro da compreensão de controle, segundo o autor, há uma bifurcação para um caráter positivo e um caráter negativo, de modo que há a localização negativa do controle, onde se fixam quadros normativos em relação ao pensamento e à escrita, o que acarreta, além das restrições, uma série de características que transformam o escrito ficcional na própria capacidade de exercer publicamente um pensamento em uma curva previsível e conformista com a realidade. Essa imediação dura de controle é sempre negativa e cerceadora, mas também, basilar dos imediatos antropológicos da civilização, por vezes exercido de modo direto como a censura comum aos regimes ditatoriais, mas também de modo socio-estrutural, como destaca o autor em entrevista oferecida à Revista Em Tese onde o autor defende que:

\begin{abstract}
Me atenho à base da pergunta. A questão do controle face à teorização. De imediato, o controle do imaginário é também um controle da teorização. Mas dizê-lo é recorrer ao aspecto fácil da questão. Em princípio, não há possibilidade de vida humana sem controle. Digo-o assim seja porque entendo que, além da acepção negativa, o controle tem um aspecto positivo. Mas a distinção ainda não é suficiente, pois o controle positivo por exemplo, a capacidade de resistir à vontade de deixar de lado as questões difíceis - rapidamente pode se transformar em negativo. Seja o caso da teorização. Como ela exige capacidade de exercício da razão, junto com sensibilidade, facilmente ela pode se desligar desta segunda e se tornar mera racionalização. A não teorização é, portanto, uma forma de controle, como a teorização pode se tornar na mesma coisa. ${ }^{1}$
\end{abstract}

A passagem nos dá o salto da outra vertente que aqui quero expressar: a capacidade desse mesmo controle que se exerce de forma negativa, como uma forma positiva. A positividade do controle se expressa no fato de termos de nos cercear para aprender e apreender o mundo dentro de nossa capacidade cognitiva. Ou ainda,

\footnotetext{
${ }^{1}$ LIMA, O direito à teoria - uma entrevista. Com Luiz Costa Lima. ANGLADA, Carolina. et PINTO, Aline Magalhães. 2017.
} 
estabelecer uma determinada objetividade sistemática e simbólica para que possamos agir e estabelecer ação no mundo da vida. Daí poderíamos pensar que ante ao absurdo ou o nãosentido (Diferentemente do non sense, o Não-sentido se apresenta como a impossibilidade de encontrar um sentido inato no mundo e seus casos e acontecimentos.) o homem que diferentemente dos animais não é dotado de um sentido instintivo ou de um aparato de instintos que o possam guiar ante a aleatoriedade do mundo da vida. Daí que a salvaguarda seja exatamente o controle, o controle positivo, que pode vir a se agudizar em uma doutrina definitiva e tornar-se negativo. Partindo assim com o sentido de que o controle positivo supõe e propõe, ao se tornar um elemento redutivo. Para o autor esse movimento é sempre um risco e um perigo, uma vez que a suposição de que as coisas dão certo faz com elas se estabilizem. Assim ocorre justamente pela impossibilidade de manter-se um aparato simbólico constate e funcional nas incontáveis estruturas narrativas e dos acontecimentos que nos cercam na esfera do real. Bem como a impossibilidade de uma teorização de tudo, uma vez que a teorização justamente necessita desses elementos isolados a serem ligados e extrapolados. Nesse sentido Luiz Costa Lima apresenta uma possibilidade outra: em vez de uma vontade ilustrada ou reflexo da divindade, surgem duas formas de lido com esse real e com o próprio pensamento: Por um lado um controle, positivo, que cerceia determinados elementos, posturas e ações e torna possível a compreensão e apreensão do mundo da vida, e por outro, o negativo, que rechaça o que sem ele, seria passível de execução.

Se por um lado o próprio Luiz Costa Lima não define os livros da Trilogia do Controle como teóricos, por outro ele abre a porta para um interessante escrutínio da relação homem mundo, se primariamente com a intenção de promover um conceito de mimesis que estabeleça (1) o ultrapasse do real enquanto elemento formativo do mímema, por outro, (2) o desarranjo do homem, desprovido de um aparato instintivo, em relação ao mundo brutal e letal que o cerca. De fato, essa não é a preocupação inicial do pensamento sobre o controle, mas há uma importante escalada e uma viragem em relação a esse pensamento que o vão deslocar em obras mais atuais, como os Eixos da Linguagem, onde o autor faz uma longa discussão envolvendo os Ensaios Sobre a Origem da Linguagem de Herder e sua teorização sobre a peculiaridade do homem frente a outros seres vivos; a um pensamento que abandona a materialidade convicta da ficção e eleva (Erhöht) à uma 
camada não hierárquica, mas definitivamente superior e mais ampla o questionamento do Ser da ficção e do efeito desta no mundo.

Em 1944, Ernst Cassirer ao ser convidado para falar de sua obra A Filosofia das Formas Simbólicas, resolve escrever um livro, mais atual e mais panorâmico do que a monumental obra original, disso resultou um conjunto de ensaios reunidos sobre o nome Ensaios Sobre O Homem Assim se sucede pois a reflexão sobre a atualidade de sua teoria lançada em 1923 o levaram ao questionamento das bases formativas que decorrem da peculiaridade do homem e do fenômeno humano. Ao tratar do Homem como animal simbólico, Cassirer sistematiza exemplarmente a esteira filosófica que percorre uma compreensão do homem para além das estruturas determinísticas ou com enfoque naturalista que eram comuns na Europa. O filósofo toma como as bases de sua argumentação filosófica a mesma conceitualidade iniciada por Herder em sua obra ensaística "Ensaios sobre a origem da linguagem" onde o homem é definido como um ser carente de cuidados e que "Não sabe que é um homem até o momento em que aprende a falar"( HERDER, 1987. Página 56.). Uma vez que o filósofo trate a linguagem como base apara a conceituação do humano, o que causa uma referencialidade complexa, pois o homem só se define enquanto tal, no momento em que se torna um ser para a linguagem, ou seja, a partir do momento em que seja capaz de traduzir em símbolos mais ou menos interligados e interativos o mundo que o cerca, uma vez que os instintos transmitidos lhe faltam, diferente dos animais; E mais tarde, na década de 1940, sistematizada por Arnold Gehlen em sua obra "Homem: Sua Natureza e sua posição no mundo" onde o ator já expressa a impossibilidade de pensar o homem como um animal como os outros animais, para ele o homem é

Nascido com habilidades tão indefinidas, dormentes, divididas e que ele [o homem] nasce exausto e aparentemente necessitado de mil necessidades, destinado a um grande círculo com as mesmas tais dispersões, enfraquecimentos e [relações] sensuais, mas ainda assim órfãos e abandonados. Mesmo a criança humana não é dotada de uma linguagem para expressar a sua necessidade - Não! Mas tal deficiência e contradição é a manutenção da natureza. Em vez dos instintos, outras forças devem dormir nele. Lacunas e Falhas não podem ser o caráter de sua espécie. (GEHLEN, 1940, P. 126)

Na breve passagem de Gehlen já fica evidenciado todo o pensamento que se forma na esteira de Herder, uma antropologia, no sentido estrito da palavra que pretende a 
compreensão do homem para além da simples existência natural. E ao localizar esse homem como uma criatura carente de cuidados (Herder) ou ainda carente de instintos (Gehlen) e de modo mais positivo, uma criatura que precisa de um aparato que não se encontre dentro de uma Umvelt ${ }^{2}$, como são os animais, que em sua existentibilidade se movem em nome de sua preservação, sem nunca ter em sentido para a sua existência, ainda que a preservação de sua vida se apoie em complexos mecanismos de ação. As três abordagens compõem um largo escopo da Antropologia Filosófica, e não haveria espaço para desenvolver toda a riqueza que delas se desenrolam.

Mas os três casos diretamente citados, em deferência a proposição de uma Umvelt nos são interessantes pelo fato incontestável da proximidade com a compreensão de Luiz Costa Lima em relação ao controle. Ora, aqui temos o primeiro ponto nevrálgico ao qual me proponho com esse texto: Luiz Costa Lima sempre esteve em uma esteira de questionamento antropológico a respeito do homem, ainda que seu foco fosse fenomenicamente o objeto literário, assim, temos uma proximidade que se evidencia entre o pensamento de Luiz Costa Lima e o arco Herder e a Antropologia Filosófica. Considerando as listagens bibliográficas das suas obras primeiras, não aparecia, como o próprio afirmou em entrevista, nada referente a antropologia filosófica e mesmo sobre a conceituação de animal/criatura carente de Herder. Apesar do crítico de Kant já aparecer em obras mais recuadas, a antropologia filosófica e a conceituação sistemática (tendo em consideração que Herder escreve um ensaio e não sistematiza de modo vertical seu conceito) sobre o mängelwesen (Criatura carente).

Mas ainda assim, o resultado teorético que é extraído de modo muito analítico segundo o próprio autor - do trabalho que se segue até o fim do último livro da Trilogia do Controle é uma compreensão de controle como um instrumento que forma (controle positivo) e deforma (Controle negativo). Mais ainda, o Controle nasce, se ousarmos aproximar ambas as linhas de pensamento, como uma redução mundo da vida à linguagem para que nele se forme um sentido que permita a interação, operação, compreensão e

\footnotetext{
${ }^{2}$ O filósofo Thure Von Uexküll, filho de Jakob Von Uexküll desenvolve uma noção de biossemiótica baseada em uma possibilidade semi-simbólica do comportamento de sistemas vivos. Prefiro o termo em alemão, pois as suas duas possíveis traduções, ambiente e ambientação ou ainda como é mais comum circunstância, não reproduzem o que explico no começo desse parágrafo.
} 
posteriormente o seu ultrapasse por meio da teoria ou da literatura, essa modalidade seria a compreensão do controle positivo.

Nesse mesmo mecanismo pró linguagem não está isento de afecções por parte da ontologia e do isolamento ontológico do Dasein, a saber, ele pode ser afetado pela metafísica, tornar-se parte da justificação do sujeito autocentrado, ser idealizado fora do mundo que o criou e se tornar uma doutrina, realizar a ficção de mundo para o ajuste ontológico dos pares opositivos... in suma a mesma estrutura estruturante que forma 0 virtuoso controle positivo, pode se voltar contra o homem e se tornar uma doutrina, ou a guisa da crítica marxista, uma ideologia.

Essa consideração já é ampla em uma conceituação definida e localizada em um arco de tempo razoavelmente curto, como é o caso da Trilogia do controle. Quando observamos uma tentativa de teorização em torno do conceito de mimesis, ou melhor dizendo em referência ao analisado, o esboço de conceito, avançamos a uma historicidade descontínua e aberta em relação a formulação da mimesis enquanto categoria reflexiva. Já enunciada desde seus primeiros trabalhos, a possibilidade de compreender a mimesis fora do enfoque sociológico já se mostrava como uma necessidade e a base do trabalho de Luiz Costa Lima. Uma vez que ao derivar à literatura um campo que está muito além da mera atitude de plasmar o real, o autor já toma um posicionamento em nome do rompimento com a sedução platônica de eleger a mimesis da linguagem literária como presa à reiteração inultrapassável do mundo que a gera.

Luiz Costa Lima elabora a sua teorização sobre a mimesis ao longo de 40 anos, já no trabalho da Trilogia do Controle aparece a preocupação quanto à mimesis como um elemento abandonado e mesmo mal compreendido no ocidente, já era argumento de que "a Mímesis literária supõe um lastro de semelhança, a que logo se acrescenta o da direferença."(LIMA, 2007, P.80) De modo que compreendemos que desde então a preocupação do autor de romper com o paradigma da imitativo e mais ainda, romper com o elemento estritamente sociológico de crítica em relação à mimesis. Como aponta Thiago Castañon Loureiro, há na proposta de Luiz Costa Lima a preocupação coma literatura para além dela mesma, uma vez que se estabelece um vinculo entre a literatura e a criticidade, onde a primeira permite o desenrolar da segunda, uma vez que a criticidade se coloca em jogo, rompendo com o paradigma platônico da substância e da ideia, Luiz Costa Lima abre a 
porta para uma criticidade que se liga umbilicalmente ao pensamento(LOUREIRO, 2013,P.6).

O que nos remete à compreensão de que a fenomenologia da mimesis proposta por Luiz Costa Lima se apoia em uma vertente Kantiana, por dois motivos, por um lado, como exposto em sua obra mais recente, $O$ insistente Inacabado, nos apresenta uma série ensaística de compreensão sobre a Mímesis, sem ser específico, mas o reconhecimento claro de ter esta como um "efeito resistente" que ao mesmo tempo resiste à razão, mas é também conformada e conformada por ela.

Na esteira de Wolfgang Iser, de quem Luiz Costa Lima era próximo e trouxe o mesmo para o Brasil, a possibilidade de uma abordagem estética da obra é (1) um exercício da razão - E aqui cabe ressaltar a proximidade com a proposição Kantiana exposta na Crítica da Faculdade de Julgar - e (2) um exercício teórico, sim, mas que se dá no efeito estético que essa obra enquanto Gegenstand (Objeto que resiste), não somente como objeto, mas como um objeto que se opõe a mim. Essa teorização se amplia logo no capítulo inicial, onde o autor faz um balanço em relação ao corte que a obra "Os Eixos da Linguagem" (2015) onde a Mímesis é arrastada, se por assim dizer, para o único terreno que Ihe cabe, o terreno da metáfora, do metafórico. Esse corte já vinha se apresentando em livros menos recentes, como o Frestas, onde Luiz Costa Lima - E aqui vale o dado biográfico - já havia passado um período sendo bolsista da Fundação Humboldt, fato que permitiu ao mesmo o contato com a corrente da Antropologia Filosófica e principalmente, com os escritos de Hans Blumenberg. Este contato causa o que chamei de corte, e por que não definir como um corte epistêmico em relação a intencionalidade de Luiz Costa Lima? A partir de agora não se considera mais uma busca por uma definição conceitual e restrita da Mímesis para além do projeto platônico de arregimentação mimética entre o controle e a imitação de um real idealizado e engajado à utilidade da Pólis. Tal arco de interpretação, segundo Luiz Costa Lima, tem uma longuíssima vida, ainda que seja atualizado em outras instâncias e com outro nome, de modo que nas suas duas obras mais recentes, Mímesis e Arredores e $O$ Insistente Inacabado o autor faz uma referência ao enfraquecimento e ao controle da Mímesis, onde sistematicamente há um tratamento que referencia as categorias de Idea, Imitatio, Verossimilhança e Representação à proposição platônica de Ideia. 
Esse importante corte nos aponta primeiramente o esforço de Luiz Costa Lima para vencer a sua ilegibilidade no panorama brasileiro, tantas vezes por ele referido, e tratado por Wlad Godzich em seu texto (GODZICH, 1999, p. 345), uma vez que o autor localiza para além do apontamento sobre o método de escrita costalimenho, que se define como "português peculiar, nem opaco nem transparente" é fruto de uma escrita que se inscreve num processo interativo no qual a origem é uma ilusão e a originalidade, um equívoco" e é claro sobre um panorama reflexivo que se apoia em bases que não fazem parte da paisagem intelectual brasileira e nem da formação dos estudos críticos aqui no Brasil. Tal esforço se pauta em uma apresentação (Ou Reapresentação) de seu panorama intelectual e de sua compreensão mais atual sobre a Mímesis onde se formam duas obras em torno do esforço de arregimentar pontos fulcrais de sua obra (Como no caso de Mímesis e Arredores) e as referências que sempre estiveram presentes em seu escopo intelectual, mas não, ou quase não, diretamente em seus textos, como se apresenta em $\mathrm{O}$ Insistente Inacabado. O esforço de Luiz Costa Lima nos apresenta como o corte epistêmico (!) que é iniciado com o deslocamento da Mímesis para o terreno da metáfora a partir da leitura de Hans Blumenberg, nos permite ver que a teorização do filósofo alemão encontramos uma libertação das amarras sócio-históricas e nos permitem pensar no texto em sua internalidade e seus efeitos. Uma vez que Blumenberg toma a metáfora para além das considerações de espira e analogia, para além dos termos de uma simples e imediata figura de linguagem que troca e desloca este e aquele sentido. Em nome da compreensão da metáfora como um campo de pensamento, como um eixo da linguagem - Se preferirmos o vocabulário de Luiz Costa Lima - e que este eixo permite, ao contrário do pensamento centrado na exclusividade do conceito como destino final do pensamento, ou seja, de uma redução das contradições e teses, a partir de uma aufhebung (Supreassunção) rumo ao conceito. A metáfora se opõe a isso, a tudo isso, pois segundo Blumenberg há uma possibilidade de expor, na metáfora signos e significações que se opõe entre eles (contradição), há um espaço para a multivocidade, sem a necessidade de acalmia ou silenciamento, como no conceito. Mas o campo da metáfora se ergue na linguagem carregando dentro de si esses elementos em uma escalada, onde, se temos no conceito puro matemático a realização máxima da filosofia, temos que na metáfora a base de toda a relação de homem-linguagem-mundo carregada de contradição, multivocidade e 
indefinição (ou uma definição momentânea), como assinala Luiz Costa Lima em Eixos da Linguagem a metáfora tem como ponto máximo a poesia/o poema. Não como unidade de forma, mas a imagem poética e como demonstrativo disse, ele [Luiz Costa Lima] lança mão de dois poemas que reúnem em si o questionamento reflexivo e que transpassados pela atividade crítica do pensamento, se tornam motores de pensamento, reflexão conceitos, por um lado evidenciando a não oposição e hierarquização dos dois eixos da linguagem que Luiz aborda, mas tomando o fenomenologia mimética em uma realização para além do racional. Como se forma nos dois poemas explorados por Luiz Costa Lima:

Caíram as estátuas de metal Qu'al se podia esperar de cousas mudas (MIRANDA, 2003, p. 302)

Ognuno Sta Solli

In Cuor dela Terra

Trafitto da un raggio di sole:

Ed é subito sera.

(QUASIMODO, 1999, p. 23)

Ambos poemas são referenciados em obras recentes de Luiz Costa Lima, na primeira poesia, na verdade um extrato de um poema de Sá Miranda, termina com uma imagem que Luiz Costa Lima explora como um caso exemplar da metaforologia de Hans Blumenberg, uma vez que o autor toma a "Metáfora como uma espécie de Enigma."13, diria mais, como um mistério que se desdobra nele mesmo, esse elemento, a metáfora, causa um movimento de explosão, que segundo Luiz Costa Lima:

A excepcionalidade deriva da aproximação de 'estátuas de metal' e 'cousas mudas'. Que se poderia justificar a metáfora (absoluta, senão explosiva) que aí se cria? Pensemos: Uma estátua que foi derrubada supõe que a figura que era celebrada foi 'dessacralizada'. Ou seja, que se tornou morta para a memória pública. Sua derrubada ressalta, pois, a morte. Melhor: como não se tornou estátua senão como em vida foi de algum modo famoso, a derrubada supõe a morte do morto. Uma dupla morte, portanto. (LIMA, 2015, p. 112)

A metáfora aqui evidenciada nesse elemento mimético de Sá de Miranda e desenvolvida via razão e derivação ao pensamento, que é o único método factível e claro nos escritos de Luiz Costa Lima, a sua abordagem teorética do mundo literário e da própria literatura, esbarra aqui no fundamento ontico da existência, se por um lado a linguagem

\footnotetext{
${ }^{3}$ Aristóteles, Retórica, 2015
} 
espira, como coloca Aristóteles, e desloca um sentido a outro, esse sentido que nasce a partir de uma aproximação, não emula, plasma ou representa o real, mas, ele se torna por um breve momento o próprio real, mas o real que não "Acalma" ao modo de Hegel as contradições, de não haver uma naturalidade entre uma estátua que fala e as "Cousas Mudas" que se sustentam menos que o bronze. Walter Benjamin escreve "Beth também é uma casa" ele não disse como uma casa, funciona como uma casa. Essa possibilidade que se abre entre o real e a metáfora nele produzida, que o move e comove é fundamental no corte a que me refiro a obra de Luiz Costa Lima, a partir da proximidade de Blumenberg a mimesis estaria nesse campo, nesse eixo da linguagem que não se funda na definição conceitual pura, mas no instante de realização, no instante poético das coisas em seu mundo, em seu próprio mundo.

A outra poesia é de Salvatore Quasimodo, Luiz Costa Lima desenvolve a sua parte final, que em deferência aos primeiros versos cortam um sentido que não está disposto na frase, como o próprio autor afirma "os dois primeiros versos de Quasimodo poderiam fazer parte de uma leitura bem banalizada que enfatizaria a solidão que cerca cada um" se o objeto mimético convive dentro de uma forma mais banal, como aponta o autor, há então uma escalada possível de ser vista, a mimesis derivaria a sua própria existência luminosa em relação ao que dela se espera, em outras palavras, o fato de que o objeto estético, em concordância com a proposição da terceira crítica Kantiana, se desenrola como uma finalidade sem fim, ou como vem propondo em seu livro mais recente Limetes onde se fala do mímema como um fim sem bordas.

No caso do poema de Quasimodo, Luiz expõe que há uma complicação em relação a atitude mimética, sem a metáfora absoluta do final não há a experiência poética que além de ligar as duas instâncias, a mimesis enfraquecida pela banalidade do poema, e a mimesis forte, a metáfora explosiva $E d$ é subito sera (E de repente, noite). Que pode passar despercebido acaso não se compreenda a multivocidade que a expressão noite, enquanto silenciamento e final de algo que era até então visto.

Essa elucubração sobre o sentido de uma metáfora que vai se encarregando de mobilizar o poético se torna uma demonstração de como Luiz passa de uma analise de profunda intuição, não no sentido comum e usual da palavra intuição, mas como na conceituação que Kant estabelece na primeira e na segunda crítica, onde a partir de 
categorias dispostas e de seus efeitos chega-se a uma formulação que suplementa a razão em nome de um conhecimento específico. A perseguição de Luiz em relação à mimesis ou como ele mesmo define, a sua obsessão pela mesma, se torna, de certa maneira, virtuosa, se tomarmos conta que o arco parte de uma busca antes ligada ao conceito, agora, em suas últimas obras, o crítico pernambucano já compreende, graças a abertura da antropologia filosófica e da metaforologia de Hans Blumenberg, uma necessidade de abertura na forma como se vem abordando a mimesis, de como ele próprio vem abordando essa fenomenologia soterrada em dois milênios e meio de tradição idealista platônica. Ao tomar a derivação da mimesis como elemento que se realiza no campo da metáfora, ou como aponta Ana Carolina Guedes, como um elemento que desloca o real dele mesmo.(GUEDES, 2017, P.48). E a isto se soma a possibilidade de pensar que a própria mimesis não se realiza somente na razão, mas convoca para si uma teorização que parte de outro arco teorético, as emoções (LIMA, 2016, P.81).

Assim delineia-se o proposito deste breve artigo, onde, tomando as duas fases da produção de Luiz Costa Lima, nos detemos em uma importante viragem, a derivação da Teoria da Mímesis rumo a sua realização no eixo linguístico da metáfora, nesse sentido, compreendemos com mais clareza a dificuldade do autor de definir a mesma como um conceito em deferência aos anteriores, limitados todos eles pela sedução platônica. Quando o autor define a mimesis como um esboço de conceito abre-se um novo precedente, a possibilidade de observar a realização da mimesis para frente, em relação a comoção de outros elementos miméticos e ao constante desenrolar de conceitos e pensamento que dela se originam. No campo do(s) saberes a partir dos desdobramentos que a crítica traz como contribuição à atualidade do pensamento antropológico (conhecimento teórico) em geral. Por outro, no campo da própria literatura, que se desenvolve uma compreensão mais profunda e humana do mundo do texto em relação ao mundo do leitor. E em outro ponto, observar o que a mimesis deixou para traz, como já foi elaborado pelo autor em relação a sua compreensão do fenômeno de arregimentação das energeias (Forças em estado bruto a serem mobilizadas para a criação) e da captação retórica que a mimesis o vai ter. Em dois textos capitais para a compreensão do que é dito, primeiro o livro Ficção e Poema (2012) e o que será lançado muito em breve Limites, as considerações do velho crítico, bem como seu acerto de contas com Freud e com os conceitos por ele mobilizados em outros escritos 
sobre literatura, mostram que o circuito de realização da mimesis se enraíza antes de mais nada, na própria condição de homem como uma criatura carente de sentido. Sabendo-se que a mimesis o se apronta em uma relação com o preparo e o desejo do observador e do próprio criador, esse elemento relativamente novo na teorização de Luiz Costa Lima se inscreve no próprio homem.

Essa consequência, por sua vez, nos dá a indicação de que, intuitivamente, Luiz Costa Lima se encaminhou teoreticamente para uma preocupação com esse esboço de conceito, que não se dá de forma gratuita ou natural, mas deriva da natureza incompleta e simbólica do homem. De modo que o pensamento antropológico (teorético) em relação a mimesis comove uma série de movimentos em relação ao próprio homem, então, daí, tiro a possibilidade de inscrever a figura de Luiz Costa Lima dentre a corrente chamada Antropologia Filosófica, ou dizer, ao menos, que sua teorização se encaminha para uma compreensão ontica do homem, rompendo com as amarras socio-históricas da crítica sociologizante, sem, no entanto, "jogar fora a criança com a água suja", Luiz Costa Lima empreende um esforço para retirar da opacidade e do soterramento, uma estrutura mimética que diz muito mais sobre o homem do que sobre suas criações.

\section{Referências Bibliográficas}

CAVALCANTI, Geraldo Holanda. Salvatore Quasimodo. Poesias. Edição Bilingue, Rio de Janeiro, Editora Record, 1999.

COLLINGWOOD, Robin Georg. An autobiography. U.K.: Oxford University Press, 2002.

GUEDES, Ana Carolina de Azevedo. 46 A metáfora como possibilidade autobiográfica: um breve ensaio In Revista Entrelaces, V. 1, No 10, Jul.-Dez. 2017.

GEHLEN, Arnold. Der Mensch. Seine Natur und seine Stellung in der Welt. Junker und Dünnhaupt, Berlin 1940.

MIRANDA, Sá. Obras Completas I. Livraria Sá da Costa Editora, abril de 2003.

GODZICH, Wlad. A ilegibilidade de Luiz Costa Lima. In: GUMBRECHT, Hans Ulrich; ROCHA, João Cezar de Castro (org.). Máscaras da mímesis: a obra de Luiz Costa Lima, Rio de Janeiro: Record, 1999. 
HERDER, Johann Gottfried . 1772. Ensaio sobre a Origem da Linguagem. Tradução de José M. Justo, Lisboa, Edições Antigona, 1987.

LIMA, Edson Silva de. Um sonho dentro de um sonho ou o novo mundo dentro de outro mundo: a nação norte americana no laboratório de Edgar Alan Poe (1809-1849). Dissertação de mestrado em História - Escola de História, Universidade Federal do Estado do Rio de Janeiro, Rio de Janeiro: 2016.

LIMA, Luiz Costa. "História, literatura e filosofia: entrevista com Luiz Costa Lima". GUEDES, Ana Carolina et Alii. In Revista de Teoria da História. Volume 20. Número 2 de 2018. Goiânia: 2018.

. Trilogia do controle. Rio de Janeiro: Topbooks, 2007.

. Os Eixos da linguagem, São Paulo, Iluminuras, 2015.

LOUREIRO, Thiago Castañon. Mímesis e crítica em Luiz Costa Lima. In Eutomia, Recife, 11 (1): 269-310, Jan./Jun. 2013.

\footnotetext{
' Doutorando/CNPO pelo Programa de pós-Graduação em História Social da Cultura da Pontifícia Universidade Católica do Rio de Janeiro, sob orientação de Luiz Costa Lima.

E-mail:ms.tannis@yahoo.com
} 